\title{
Managing BRCA Mutation Carriers in China: Reply
}

\author{
Ava Kwong • Enders K. O. Ng
}

Published online: 18 November 2010

(C) The Author(s) 2010. This article is published with open access at Springerlink.com

The reply from Kalogerakos [1] to our article has highlighted the importance of the need to understand the risk conferred by BRCA mutation carriers in Chinese and other ethnic groups in order to achieve personalized medicine. Guidelines for prophylactic interventions and intensive surveillance are based on studies performed mainly in Caucasian cohorts. BRCA1 and BRCA2 mutation carriers have a 4.5-fold and 3.4-fold increased risk of getting contralateral breast cancer. The relative risk of contralateral breast cancer in BRCAl mutation carriers increases as the age at first diagnosis decreases, and can be as high as 11 -fold if the age at first diagnosis of breast cancer is under 35 [2]. Occult invasive cancers found in prophylactic mastectomy specimens ranges from 0.7 to $10.7 \%$. Prophylactic mastectomy is found to be effective in preventing invasive breast cancer in $B R C A$ mutation carriers as the remaining risk is less than $0.2 \%$ per woman-year [3]. Similarly, salpingo-oophorectomy significantly reduces the risk of breast cancer (hazard ratio $[\mathrm{HR}]=0.36-0.63$ ) and ovarian or fallopian tube cancer $(\mathrm{HR}=0.14-0.28)$ in $B R C A$ mutation carriers. There is also reduction in breast cancer $(\mathrm{HR}=0.44)$ and ovarian cancer-specific mortality $(\mathrm{HR}=0.21)$ [4]. However, there is limited information on $B R C A 2$ mutation carriers since it is less common in

\footnotetext{
A. Kwong $(\bowtie) \cdot$ E. K. O. Ng

Division of Breast Surgery, Department of Surgery,

The University of Hong Kong Li Ka Shing Faculty of Medicine,

Pokfulam, Hong Kong

e-mail: akwong@asiabreastregistry.com

A. Kwong

Department of Surgery, Stanford University School of Medicine, 300 Pasteur Drive, \# Mc5640, Stanford, CA 94305-2296, USA
}

Caucasian cohorts. Because of a lower incidence of breast cancer in Chinese ( 1 in 20) and also a higher BRCA2 detection rate found in our study, risk in this group is likely to be different. Therefore, it is important to have more precise ethnicity-specific estimates of specific risks so that more accurate guidelines based on the efficacy of riskreducing interventions, surveillance, and use of novel drugs such PARP inhibitors can be made.

Next-generation sequencing technology (also known as massive parallel sequencing) allows the development of studies unachievable a few years ago. Nowadays, nextgeneration sequencing technology provides an unprecedented ability to search for mutations, copy number aberrations, and somatic rearrangements in an entire cancer genome at base pair resolution which can be performed in a matter of weeks. By comparing BRCA mutations carriers who do not develop cancer with those who do, it may be possible to identify novel genetics changes associated with development of BRCA-related breast/ovarian and related cancers. As sequencing capacity improves, scientists will move forward from one genome per individual to multiple genomes per individual from sources including precancerous cells and cancer cells. Furthermore, recent genomewide association studies using high-throughput human SNP arrays also identified new breast cancer susceptibility genes which can increase cancer risk prediction [5, 6]. As the complexity of assessing cancer risk genetically increases in technology and knowledge of ethnic differences, clinical recommendations will need to be standardized and personalized accordingly.

Open Access This article is distributed under the terms of the Creative Commons Attribution Noncommercial License which permits any noncommercial use, distribution, and reproduction in any medium, provided the original author(s) and source are credited. 


\section{References}

1. Kalogerakos K (2010) Managing BRCA mutations in China [letter]. World J Surg 34: doi:10.1007/s00268-010-0788-6

2. Malone KE, Begg CB, Haile RW et al (2010) Population-based study of the risk of second primary contralateral breast cancer associated with carrying a mutation in BRCA1 or BRCA2. J Clin Oncol 28(14):2404-2410

3. Kaas R, Verhoef S, Wesseling J et al (2010) Prophylactic mastectomy in BRCA1 and BRCA2 mutation carriers: very low risk for subsequent breast cancer. Ann Surg 251(3):488-492
4. Domchek SM, Friebel TM, Singer CF et al (2010) Association of risk-reducing surgery in BRCA1 or BRCA2 mutation carriers with cancer risk and mortality. JAMA 304(9):967-975

5. Thomas G, Jacobs KB, Kraft P et al (2009) A multistage genomewide association study in breast cancer identifies two new risk alleles at 1p11.2 and 14q24.1 (RAD51L1). Nat Genet 41(5): 579-584

6. Turnbull C, Ahmed S, Morrison J et al (2010) Genome-wide association study identifies five new breast cancer susceptibility loci. Nat Genet 42(6):504-507 